\title{
Changes in the parameters of the anterior segment of the eye in pregnant women - literature review
}

\author{
Karol Taradaj ', Tomasz Ginda' ${ }^{1}$, Piotr Ciechanowicz' ${ }^{1}$ Piotr Maciejewicz², Barbara Suchońska², \\ Iwona Szymusik², Bożena Kociszewska-Najman², Mirosław Wielgoś2 , Dariusz Kęcik \\ ${ }^{1}$ Department of Ophthalmology, Medical University of Warsaw, Poland \\ ${ }^{2} 7^{\text {st }}$ Chair and Department of Obstetrics and Gynecology, Medical University of Warsaw, Poland
}

\begin{abstract}
The physiology of pregnancy is a curious issue for specialists from different branches of medicine and science. In this systematic review, the attention was focused on changes in eyes during pregnancy and confinement. To summarise and systematize actual knowledge in eyes' changes during pregnancy, publications from years 2011-2017 were analysed. Studies about parameters of corneal endothelial cells, corneal biomechanical parameters, keratometric variables, intraocular pressure and biometry of the anterior chamber were compared. The conducted studies demonstrated the unambiguous character of changes only in case of intraocular pressure, which decreased during the II and III trimesters of pregnancy. Inconsistent study methods and low number of examined patients did not enable to draw explicit conclusions in context of other parameters of the anterior segment of the eye in pregnant women. It is indicated to perform further studies on a representative and homogeneous group of female patients.
\end{abstract}

Key words: pregnancy, labour, cornea, keratometry, anterior chamber, intraocular pressure

Ginekologia Polska 2018; 89, 3: 168-172

\section{INTRODUCTION AND AIM}

Pregnancy is a period of intense changes occurring in women's organism when hormone balance is modified. These changes concern all systems and organs. They also affect the organ of vision - both the anterior and the posterior segment of the eye [1-3].

The aim of this study is to summarize and systematize the knowledge on the changes in anatomy and physiology of the anterior segment of the eye, based on the analysis of current literature.

The following parameters were analysed:

- parameters of corneal endothelial cells: CD - cell density, \%HEX - the percentage of hexagonal cells, CV - coefficient of variation.

- pachymetric parameters:CCT — central corneal thickness

- keratometric parameters: K1, K2, mean K(K1 - flat parameter, K2 - steep parameter, mean K - mean parameter).

- biomechanic parameters: $\mathrm{CH}$ - corneal hysteresis, CRF - corneal resistance factor
- tonometric parameters: IOP - intraocular pressure, Goldmann-correlated IOP, corneal-correlated IOP

- biometric parameters of the anterior chamber: ACD - anterior chamber depth, ACV - anterior chamber volume, ACA - anterior chamber angle.

\section{METHODS}

Systematic review included the articles published in 2011-2017. Search was conducted according to the following keywords: parturition \& eye, labour \& eye, labour \& cornea, cornea \& delivery, cornea \& childbirth, cornea $\&$ pregnant woman, intraocular pressure \& delivery, intraocular pressure \& pregnancy, cornea \& pregnancy in the MESH system and in the other systems. The search system included the participation of two independent researchers. Articles published in the Embase, Medline and Cochrane databases were included in the analysis. All the articles were read in full-text version. No language restrictions were applied. 


\section{PACHYMETRY AND KERATOMETRIC PARAMETERS: CCT, K1, K2}

Changes in central corneal thickness during pregnancy bring the attention of many researchers. A mechanism that affects $C C T$ is not entirely known. Keratometric parameters change during the menstrual cycle. As it was demonstrated in the studies by Giufree et al. [4] and Goldich et al. [5], cornea is the thinnest in the first days of menstrual cycle, and the thickest during the last days of menstrual cycle. Additionally, taking into consideration the fact that corneal epithelial cells contain oestrogen, progesterone and androgen [6] receptors, it seems very probable that changes in corneal parameters may be evoked by fluctuations in sex hormone levels. In spite of conducting studies with participation of pregnant women, the results are not unambiguous. Atas et al. [7], studying a group of 54 women, demonstrated an increase in corneal thickness in the III trimester of pregnancy compared to the study performed three months after delivery $(539.85 \mu \mathrm{m} \pm 33.38$ vs. $535.69 \mu \mathrm{m} \pm 34.95)(p<0.001)$. Efe et al. [8], in their study conducted on a group of 25 women (50 eyes) followed a dynamic of changes in CCT between the 10 weeks of pregnancy and the 3-months postpartum. They proved the presence of a significant $(p<0.001)$ thickening in the central part of cornea in the II and III trimesters of pregnancy, compared to the measurements carried out in the 3 months after delivery $(566.64 \mu \mathrm{m} \pm 21.99$ and $573.68 \mu \mathrm{m} \pm 24.03$ vs. $562.49 \pm 23.40 \mu \mathrm{m}$ respectively) ( $p<0.005)$. Publications by Goldich et al. [9], Sen et al. [10], and Naderan et al. [11], who claim that CCT does not change during pregnancy, are in opposition to the above-mentioned studies.

Assessment of corneal thickness is an important parameter in the description of the anterior segment of the eye. Not taking CCT into consideration may lead to a distortion of IOP measurement. Wrong diagnosis of ocular hypertension - the main risk factor of glaucoma, can contribute to implementation for unjustified anti-glaucoma treatment.

In medical databases there are also publications concerning a subject of changes in keratometric parameters: $\mathrm{K} 1, \mathrm{~K} 2$, mean K. Similar as in the case of CCT, the researchers do not agree on the direction of changes in these parameters during pregnancy. Atas et al. [7], basing on a 54-member group of pregnant women, demonstrated significant $(p<0.05)$ differences in all three keratometric parameters (K1, K2, mean $\mathrm{K}$ ) in the III trimester of pregnancy compared to the examination in the 3 months after delivery. Goldich et al. [9], obtained a statistically significant difference concerning only K2 parameter in pregnant women (60 eyes) compared to non-pregnant women $(p=0.039)$. Other studies $[9,11]$, taking into account the results of a total of 95 pregnant women, did not show any significant changes in keratometric parameters during pregnancy. In conclusion, the variability of K1, K2 and mean K parameters was not definitively assessed. Observation concerning a tendency [9] of K2 to increase during pregnancy is an indication for conducting further studies.

\section{CORNEAL ENDOTHELIUM CELLS}

Corneal endothelium, that actually is a single layer squamous epithelium, constitutes the innermost corneal layer. It is composed of a single layer of hexagonal cells that, among others, control the proper hydration of corneal stroma. Endothelium together with Descemet's membrane and probably with Dua's layer create the endothelial barrier [12]. Thanks to the properties of endothelial cells, corneal oedema and decrease in visual acuity do not occur. Such parameters of endothelial cells as number, shape and size change during lifetime. Endothelial cells do not have regenerative properties, that is conditioned by the histological structure of this layer, so together with a pathological decrease in their number, corneal decompensation can occur [13].

In the course of conducted literature analysis, detailed studies assessing changes in parameters of endothelial cells in pregnant women have not been found. Ornek et al. [14], were the first who attempted to investigate the changes in parameters of endothelial cells during pregnancy. In the group of 66 pregnant women divided into 3 study subgroups (I, II and III trimester of pregnancy), they observed an increase in cell density (CD) in the II and III trimesters compared to the control group composed of non-pregnant women adjusted by age. In spite of assessment of the tendency, these changes were not statistically significant $(p>0.05)$. Another studied parameter - \%HEX was increased in all the trimesters of pregnancy. However, these changes were statistically significant compared to the group of non-pregnant women $(p<0.05)$ only in the I trimester. CV exhibited a significant increase in the I trimester $(p<0.05)$ and a decrease in the II and III trimesters ( $<<0.05)$. According to the authors, methodology of the study by Ornek et al. [14] was not planned properly. Precise tracing the dynamics of changes in the parameters of corneal endothelial cells requires conducting prospective studies, in which one group of patients would be examined several times during pregnancy and after delivery. Study design applied by the authors [14] did not consider the fact that some of the patients used contact lenses. As it results from the studies by Lee et al. [15], in patients using contact lenses a percentage of hexagonal cells decreases. If this vital element of medical history is not taken into account, it can disturb the results and lead to wrong conclusions. Conducting further studies is essential in order to confirm the tendencies of changes in parameters of corneal endothelial cells during pregnancy. 


\section{INTRAOCULAR PRESSURE}

Various methods of IOP measurement are used in clinical practice, including applanation and impression tonometry [16]. In recent years, there has been a significant technological progress in the methods of measurement of intraocular pressure [17]. Goldmann applanation tonometer, that is still a gold standard in IOP examination, is standardized for corneal thickness of $520 \mu \mathrm{m}$. In thinner corneas, readings of IOP measurements are understated and in patients with corneas thicker than this value - the measurements are overstated. In such situations, values should be appropriately subtracted or added according to the nomograms. Nomogram for Goldmann tonometer is presented in Table 1.

A method of correlation of IOP results differs depending on the device. Due to this, it is not possible to indicate one, fully reliable measurement method for IOP assessment. Devices that correct the value of intraocular pressure with regard to corneal biomechanics are a good solution increasing the precision of measurement.

The subject literature describes studies assessing the value of intraocular pressure in the individual trimesters of pregnancy and after delivery.

Despite using different study methodology, results from all of the authors indisputably indicate a decreasing tendency of intraocular pressure in pregnant women compared to the non-pregnant female patients.

Tolunay et al. [19] investigated a group of 235 women divided into 4 groups: the I, the II, the III trimester and the postpartum period. Using Goldmann tonometer, they demonstrated that IOP value in the II and III trimesters of pregnancy is significantly lower than in the I trimester and during the postpartum period $(p=0.006, p<0.001$ and $p=0.001$ respectively). A similar relationship can be observed in the studies by Efe et al. [8], who used the Canon TX-F non-contact tonometer to demonstrate a decrease in IOP in the II and III trimesters of pregnancy compared to the I trimester and to the 3 months after delivery ( $p=0.001$, ANOVA).

Other authors, such as Sen [10] and Goldich [9], applied in their studies a Reichert Ocular Response Analyzer (ORA), considering biomechanical properties of the cornea. Despite the fact that values of IOP measurements obtained with the use of this method (IOPg, IOPcc) are higher in terms of absolute value than in case of Goldmann tonometry, the results of both studies confirm the tendency described by Tolunay [19] and Efe [8].

Goldich et al. [9] demonstrated a decrease in IOPg, IOPcc in the group of pregnant women in comparison to the control group $(p<0.001)$. Similar results were obtained by Sen et al. [10] (plOPg $=0.001, \mathrm{plOPcc}=0.0001$, Kruskal-Wallis test).

The mechanism of IOP decrease during pregnancy was not completely explained. It is assumed that increased concentrations of oestrogen, relaxin, progesterone and $\beta-\mathrm{HCG}$ enhance the outflow of aqueous humour via the unconventional way. That decrease may be also caused by pressure reduction in the episcleral veins during pregnancy.

\section{BIOMECHANICAL PARAMETERS OF THE CORNEA: CH AND CRF}

New measurement techniques enable to examine a larger number of corneal parameters. The non-contact tonometer Reichert Ocular Response Analyzer (ORA) mentioned above allows the measurement of corneal hysteresis and corneal resistance factor. Hysteresis is a measure of viscoelastic properties of the cornea. According to a general relationship, the thinner and more delicate the tissue, the lower the hysteresis (cornea returns to its primary shape more quickly after two-time applanation with the use of stream of air). The above-mentioned examinations taking into consideration changes in other parameters, such as CCT and IOP, during pregnancy might suggest illustrating

Table 1. Intraocular pressure nomogram for Goldman applanation tonometry examination [18]

\begin{tabular}{|c|c|c|c|}
\hline CCT (micrometers) & IOP Adjustment $(\mathbf{m m H g})$ & CCT (micrometers) & IOP Adjustment (mmHg) \\
\hline 445 & +7 & 545 & 0 \\
\hline 455 & +6 & 555 & -1 \\
\hline 465 & +6 & 565 & -1 \\
\hline 475 & +5 & 575 & -2 \\
\hline 485 & +4 & 585 & -3 \\
\hline 495 & +4 & 595 & -4 \\
\hline 505 & +3 & 605 & -4 \\
\hline 525 & +2 & 615 & -5 \\
\hline 535 & +1 & 625 & -6 \\
\hline
\end{tabular}

IOP — measurement depends on biomechanical parameters of cornea 
those changes just in $\mathrm{CH}$ and CRF. However, the trials that have been already conducted with the use of ORA, do not confirm that thesis.

Naderan and Jahanrad [11], investigating the group of 70 pregnant women prior to pregnancy, in the III trimester and one year after delivery, did not observe any significant differences in $\mathrm{CH}$ and $\mathrm{CRF}$ compared to the control group ( $p>0.05$ ANOVA). Similar conclusions result from the studies (Goldich et al. [9] and Sen et al. [10]). In both cases changes in $\mathrm{CH}, \mathrm{CRF}$ parameters are not statistically significant $(\mathrm{p}>0.05)$.

Correlation of these parameters relative to biometric measurement and IOP remains the subject of studies. According to Lopez de la Fuente et al. [20], there is an average negative correlation between IOPcc and $\mathrm{CH}$ measured in the patient $(r=-0.482)$. That conclusion was confirmed by studies $[9,10]$, where higher $\mathrm{CH}$ values were obtained for lower IOPcc measurements. Analogically, there is a high positive correlation for IOPg and CRF ( $r=0.619)$. Results worked out by Sen et al. [10] do not confirm this thesis. Together with a decrease in IOPg in the following trimesters of pregnancy, Sen [10] observed an increase in CRF.

The divergence in data shows that further studies on the assessment of the relationship between the parameters tested using ORA and the remaining tonometric parameters are necessary.

\section{BIOMETRIC PARAMETERS OF THE ANTERIOR CHAMBER: ACD, ACA, ACV}

Apart from the variables discussed above, the parameters of the anterior chamber including ACD, ACV and ACA are also worth noting. There is only one study [7] in the subject literature that describes a change in depth, volume and angle of the anterior chamber during pregnancy. The studies by Atas et al. [7] were conducted on a group of 54 women in the 3 trimester of pregnancy. The measurements were carried out using Scheimpflug camera (Pentacam system) in the third trimester of pregnancy and 3 months after delivery. It was shown that values of all the parameters of the anterior chamber are higher in the third trimester of pregnancy compared to the third month after delivery. The analysis performed using Student's t-test for correlated samples demonstrated that the differences were statistically significant $\left(\mathrm{p}_{\mathrm{ACD}}<0.001, \mathrm{p}_{\mathrm{ACA}}=0.002, \mathrm{p}_{\mathrm{ACV}}<0.001\right)$. The literature is lacking in other studies describing changes in values of those parameters during pregnancy.

Apart from the cited article [7], there is no explicit proof in the literature concerning the influence of pregnancy on ACD, ACA, ACV. Increasing depth, volume and angle of the anterior chamber in the III trimester can be analogically referred to menstrual cycle. Karatepe et al. [21], based on their studies, revealed that ACV and ACA remain on the constant level regardless the phase of the cycle, whereas ACD significantly $(p<0.05)$ increases in the 26 day compared to the first day of the cycle. It is interesting that in the studies by Atas et al. [7] all the mentioned parameters of the anterior chamber increase in the III trimester of pregnancy.

On that basis, it can be stipulated that changes in the biometric parameters of the anterior chamber result from the increase in concentration of sex hormones during pregnancy. However, that interesting hypothesis requires confirmation in additional studies conducted on a larger group of female patients.

\section{SUMMARY}

In the course of pregnancy, the value of intraocular pressure decreases. A decrease in this parameter is most noticeable in the II and III trimesters of pregnancy compared to the postpartum period. This phenomenon probably has hormonal origin. A tendency to decreasing of IOP should be taken into consideration during control ophthalmological examinations of pregnant women. Varying value of CCT, demonstrated by some of the researchers, can also affect the result of pressure measurement.

In view of divergence in results of the studies analysing changes in anatomical parameters of the anterior segment of the eye in pregnant women, there is a need to undertake further studies, extended with the use of a larger, more homogeneous study group.

\section{REFERENCES}

1. Yenerel NM, Kucumen RB. Pregnancy and the eye. Turk J Ophthalmol. 2015: Oct 45(5): 213-219, doi: 10.4274/tjo.43815, indexed in Pubmed: 27800235

2. Dewundara S, Wiggs J, Sullivan DA, Pasquale LR. Is Estrogen a Therapeutic Target for Glaucoma? Semin Ophthalmol. 2016; 31(1-2): 140-146, doi: 10.3109/08820538.2015.1114845, indexed in Pubmed: 26959139

3. Akar Y, Yucel I, Akar ME [et al.]. Menstrual cycle-dependent changes in visual field analysis of healthy woman. Opthalmologica. 2005 Jan-Feb; 219(1):30-5, doi: 10.1159/000081780, indexed in Pubmed: 15627825

4. Giuffrè $G$, Di Rosa L, Fiorino $F$ [et al.]. Variations in central corneal thickness during the menstrual cycle in women. Cornea. 2007; Feb;26(2):144-6, doi: 10.1097/01.ico.0000244873.08127.3c, indexed in Pubmed: 17251801

5. Goldich Y, Barkana Y, Pras E [et al.] Variations in corneal biomechanical parameters and central corneal thickness during the menstrual cycle. J Cataract Refract Surg. 2011; Aug;37(8):1507-11, doi: 10.1016/j. jcrs.2011.03.038, indexed in Pubmed: 21782094

6. Suzuki T, Kinoshita Y, Tachibana M [et al.]. Expression of sex steroid hormone receptors in human cornea. Curr Eye Res. 2001 Jan;22(1):28-33, indexed in Pubmed: 11402376

7. Atas M, Duru N, Ulusoy DM [et al.]. Evaluation of anterior segment parameters during and after pregnancy. Contact Lens \& Anterior Eye 37 (2014) 447-450, doi: 10.1016/j.clae.2014.07.013, indexed in Pubmed: 25128198

8. Efe YK, Ugurbas SC, Alpay A, MD, Ugurbas SH. The course of corneal and intraocular pressure changes during pregnancy. Can J Ophthalmol—vol. 47, No. 2, April 2012, doi: 10.1016/j.jcjo.2012.01.004, indexed in Pubmed: 22560420

9. Goldich, Y., Cooper, M., Barkana, Y [et al.]. Ocular anterior segment changes in pregnancy. J Cataract Refract Surg. 2014;40:1868-1871, doi: 10.1016/j.jcrs.2014.02.042, indexed in Pubmed: 25217070

10. Sen E, Onaran Y, Nalcacioglu-Yuksekkaya P, Elgin U, Ozturk F. Cornea biomechanical parameters during pregnancy. Eur J Ophthalmol 2013;00 (00): 000-000, doi: 10.5301/ejo.5000378, indexed in Pubmed: 24170521

11. Naderan $M$, Jahanrad A. Anterior, posterior and biomechanical parameters of cornea during pregnancy in healthy eyes: a cohort study. 
Br J Ophthalmol. 2017 Jul 29. pii: bjophthalmol-2017-310247, doi: 10.1136/bjophthalmol-2017-310247, indexed in Pubmed: 28756375

12. Dua HS, Faraj LA, Said DG [et al.]. Human corneal anatomy redefined: a novel pre-Descemet's layer (Dua's layer). Ophthalmology. 2013 Sep;120(9):1778-85, doi: 10.1016/j.ophtha.2013.01.018, indexed in Pubmed: 23714320

13. Naumann GO, Schlötzer-Schrehardt U. Keratopathy in pseudoexfoliation syndrome as a cause of corneal endothelial decompensation: a clinicopathologic study. Ophthalmology. 2000 Jun;107(6):1111-24, indexed in Pubmed: 10857831

14. Örnek N1, Özcan Dağ Z, Örnek K. Corneal Endothelial Cell Density and Morphology in Different Trimesters of Pregnancy. Eye Contact Lens. 2017 Jan 4, doi: 10.1097/ICL.0000000000000354, indexed in Pubmed:28060145

15. Lee JS1, Park WS, Lee SH [et al.]. A comparative study of corneal endothelial changes induced by different durations of soft contact lens wear. Graefe's Arch Clin Exp Ophthalmol (2001) 239:1-4, indexed in Pubmed: 11271455

16. Okafor KC, Brandt JD. Measuring intraocular pressure. Curr Opin Ophthalmol. 2015 Mar;26(2):103-9, doi: 10.1097/ICU.0000000000000129, indexed in Pubmed: 25594767
17. Garcia-Feijoo J, Martinez-de-la-Casa JM, Morales-Fernandez L [et al.]. New technologies for measuring intraocular pressure. Prog Brain Res. 2015;221:67-79, doi: Prog Brain Res. 2015;221:67-79. doi: 10.1016/bs.pbr.2015.06.003, indexed in Pubmed: 26518073

18. Patwardhan AA, Khan M, Mollan SP, [et al.]. The importance of central corneal thickness measurements and decision making in general ophthalmology clinics: a masked observational study. BMC Ophthalmology. 2008;8:1. doi:10.1186/1471-2415-8-1, indexed in Pubmed: PMC2258278

19. Tolunay, H., Özcan, S., Şükür, Y. [et al.]. Changes of intraocular pressure in different trimesters of pregnancy among Syrian refugees in Turkey: A cross-sectional study. Turk J Obstet Gynecol. 2016 Jun;13(2):67-70, doi: 10.4274/tjod.40221, indexed in Pubmed: 28913094

20. Lopez de la Fuente $C$, Sanches-Cano A, Pinilla I [et al.] Relationship between IOP and biomechanical corneal values obtained by ORA. Acta Ophthalmol. 2012 Sep. Vol. 90 Issue s249, doi: 10.1111/j.17553768.2012.F004.x

21. Karatepe AS; Onay MP, Eğrilmez S, Yağcı A. Menstrüel Siklusun Ön Kamara Parametreleri Üzerine Etkisinin Pentacam ile Araştırılması. Turkish Journal of Ophthalmology. Jan/Feb2013, Vol. 43 Issue 1, p15-18. 4p. 1 Chart, 2 Graphs 